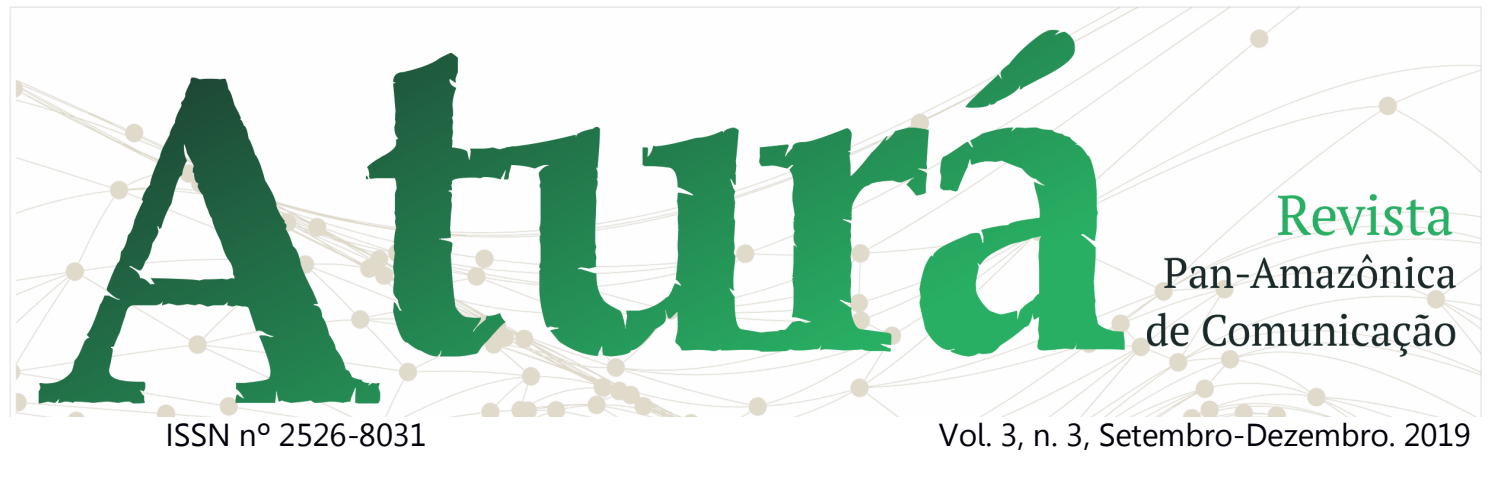

\title{
RUAS DE MILITARES EM VILHENA-RO: HISTÓRIA E COMPOSIÇÃO DO ESPAÇO URBANO
}

Military Streets in Vilhena-RO: History and Composition of Urban Space

Calles Militares en Vilhena-RO: Historia y Composición del Espacio Urbano

\section{Allysson Viana Martins ${ }^{1}$ \\ Maria Victória Silva ${ }^{2}$}

\section{RESUMO}

Nascida no período da ditadura militar, a cidade de Vilhena tem suas histórias e memórias visíveis na constituição de espaços públicos locais. O município possui atualmente uma escola cujo nome faz referência aos ditadores militares, a Escola Municipal de Ensino Fundamental Castelo Branco, além de 9 ruas e 6 avenidas que homenageiam militares de diferentes épocas. Aqui, discutimos os conceitos de história, lugares de história e espaço urbano. Este trabalho visa a investigar, a partir da cartografia da cidade, os resquícios históricos de sua ocupação na construção dos espaços públicos.

PALAVRAS-CHAVE: História; Ruas; Militares; Vilhena; Rondônia.

\footnotetext{
ABSTRACT

Born in the period of the military dictatorship, the city of Vilhena has its stories and memories visible in the constitution of local public spaces. The municipality currently has a school whose

1 Professor do curso de Jornalismo e coordenador do COMtatos - Grupo de Pesquisa em Espaços e Temporalidades Comunicacionais da Universidade Federal de Rondônia (UNIR). Doutor em Comunicação e Cultura Contemporâneas pela Universidade Federal da Bahia (UFBA). E-mail: allyssonviana@unir.br.

2 Jornalista. Graduada no curso de Jornalismo da Universidade Federal de Rondônia (UNIR). E-mail: mariavictoriafs@hotmail.com.
} 


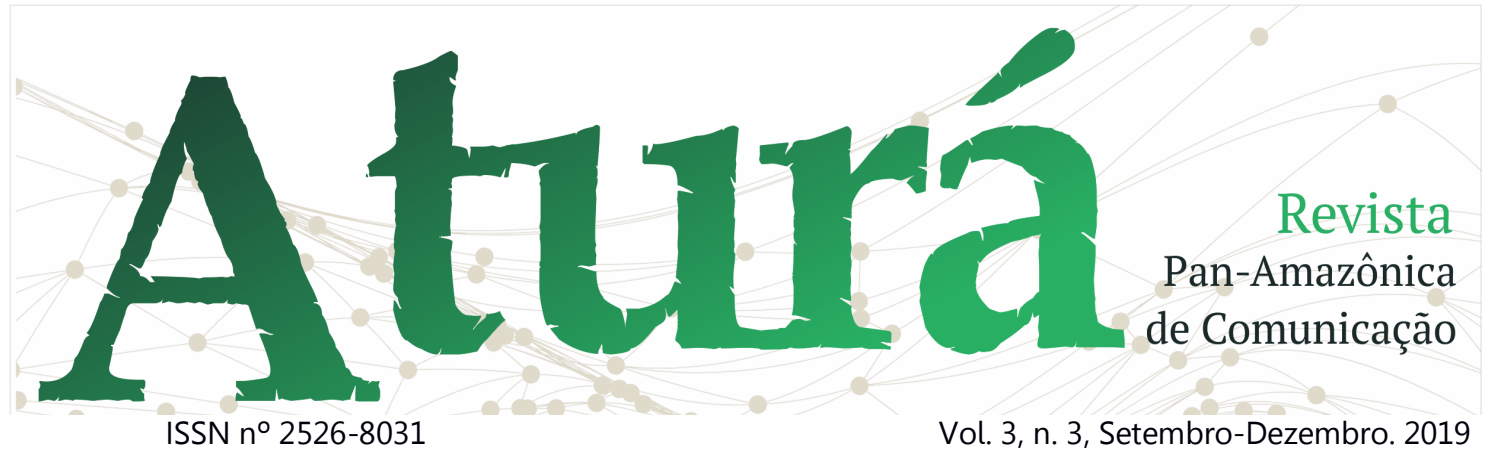

name refers to military dictators, the Castelo Branco Municipal Elementary School, as well as 9 streets and 6 avenues that honor military personnel from different eras. Here we discuss the concepts of history, places of history and urban space. This work aims to investigate, from the city's cartography, the historical remains of its occupation in the construction of public spaces.

KEYWORDS: History; Streets; Military; Vilhena; Rondonia.

\section{RESUMEN}

Nacida en el período de la dictadura militar, la ciudad de Vilhena tiene sus historias y recuerdos visibles en la constitución de los espacios públicos locales. El municipio actualmente tiene una escuela cuyo nombre se refiere a dictadores militares, la Escuela Primaria Municipal Castelo Branco, así como 9 calles y 6 avenidas que honran al personal militar de diferentes épocas. Aquí discutimos los conceptos de historia, lugares de historia y espacio urbano. Este trabajo tiene como objetivo investigar, desde la cartografía de la ciudad, los restos históricos de su ocupación en la construcción de espacios públicos.

PALABRAS CLAVE: historia; Calles Personal militar; Vilhena Rondonia.

Recebido em: 15.06.2019. Aceito em: 09.08.2019. Publicado em: 01.09.2019. 


\section{A \\ ISSN n 2526-8031 \\ Vol. 3, n. 3, Setembro-Dezembro. 2019}

\section{Introdução}

As principais cidades de Rondônia, estado localizado na região Norte do país, foram formadas a partir dos Projetos Integrados de Colonização (PICs). Esses municípios atraíram imigrantes, principalmente do Sul e Sudeste do país, que se tornaram a elite agrícola da região. Em torno dessas migrações, foram construídas cidades que buscam avançar, ano após ano, em infraestrutura urbana, que se beneficiam da instalação de crescentes redes de beneficiamento de recursos naturais $e$ agrícolas.

Os migrantes fugiam, normalmente, da escassez e dos conflitos agrários em outras regiões do Brasil. A leva migratória que deu início à cidade de Vilhena, no entanto, contou ainda com o incentivo do governo militar da época, porém os municípios de Rondônia, localizados ao longo da BR-364, tiveram também a influência da abertura das Linhas Telegráficas Estratégicas de Mato Grosso ao Amazonas, coordenada pelo oficial do Corpo de Engenharia do Exército, Cândido Mariano da Silva Rondon, anos antes.
Em Rondônia, três cidades tiveram origem e se tornaram vilarejos por conta dos trabalhos da Comissão Rondon, sendo Vilhena uma delas, cujo nome faz referência a Álvaro Coutinho de Melo Vilhena, amigo de Marechal Rondon e diretor-geral dos Telégrafos (Fiori, 2012). A história do município começa oficialmente em 11 de outubro de 1977 com o artigo $47^{\circ}$ da Lei $n^{\circ}$ 6.448, assinado pelo então presidente da República, Ernesto Geisel e teve como primeiro prefeito Renato Coutinho dos Santos, que administrou o município até março de 1980.

A cidade de Vilhena se tornou diferente das outras do estado. O local era de certa forma privilegiado, por sua proximidade, de cerca de 700 quilômetros, da capital de Rondônia, Porto Velho, e da capital mato-grossense, Cuiabá. As estratégias militares de ocupação da Amazônia fizeram com que o município crescesse, como os outros no estado, porém algumas peculiaridades como o clima e o solo puderam ser percebidas em Vilhena desde 0 início de sua ocupação. Transformada em base de apoio para a 


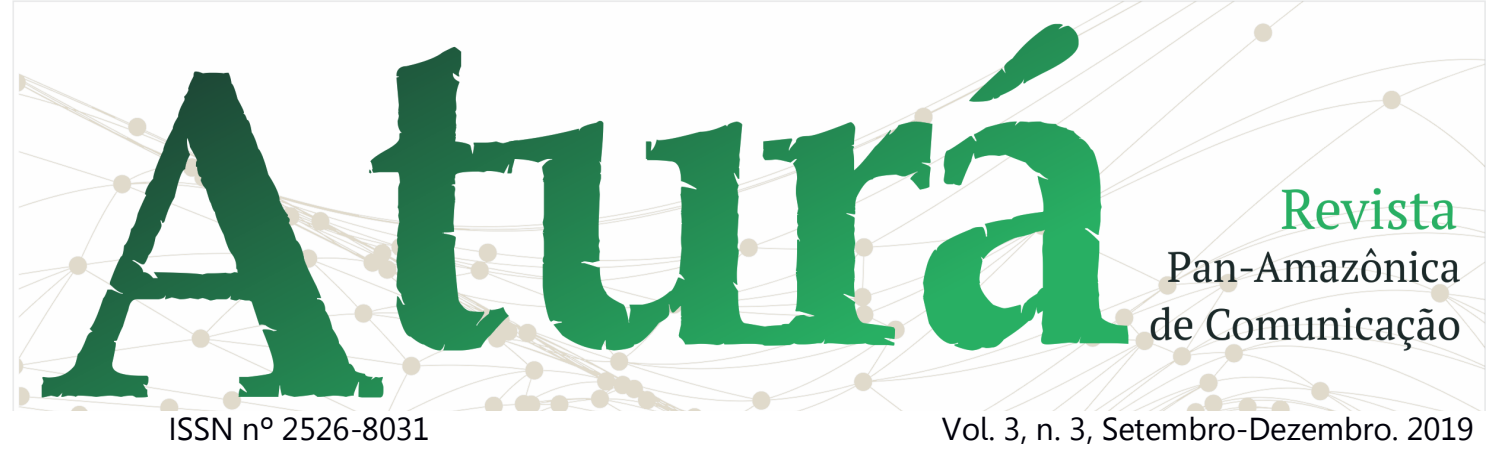

construção da BR-364, o número de trabalhadores começou a crescer na região. Com as obras da rodovia, foi construída uma pista de pouso para aviões, visando apoiar a abertura da BR-364, dando a Vilhena certa vantagem em termos de desenvolvimento em relação as outras cidades do estado (FIORI, 2012).

Entre os anos de 1964 e 1966, já no início da ditadura militar, foram instalados, naquela pequena vila, o $5^{\circ}$ Batalhão de Engenharia e Construção, um destacamento da Força Aérea Brasileira e um pequeno hospital militar, além da primeira serraria e do início das obras da Embratel. A cidade se tornou distrito de Porto Velho, capital de Rondônia, em 1 de abril de 1969, pelo Decreto $n^{\circ} 565$. Com cerca de 160 casas e as avenidas Marechal Rondon, Major Amarante e Capitão Castro, a cidade continuava a crescer e teve sua emancipação em 23 de novembro de 1977, com a Lei $\mathrm{n}^{\circ}$ 6.448, sancionada pelo então presidente Ernesto Geisel.

Nascida no período da ditadura
militar, Vilhena tem suas histórias e
memórias visíveis desse período na

Nascida no período da ditadura memórias visíveis desse período na constituição do espaço público local. O município possui atualmente uma escola cujo nome faz referência aos ditadores militares, a Escola Municipal de Ensino Fundamental Castelo Branco, além de 9 ruas e 6 avenidas que homenageiam militares de diferentes épocas. Este trabalho representa a primeira etapa de uma pesquisa mais ampla, que visa a investigar, a partir da cartografia da cidade, os resquícios de sua ocupação na construção do espaço público. Aqui, discutimos os conceitos de história, lugares de história e espaço urbano, a fim de identificar de que maneira eles podem ser pensados a partir da cidade de Vilhena, interior de Rondônia.

\section{História}

O termo história pode referir-se a dois aspectos: a ciência histórica e os acontecimentos passados.

1) "procura das ações realizadas pelos homens" (Heródoto) que se esforça por se constituir em ciência, a ciência histórica; 2 ) o objeto de procura é o que os homens realizaram. [...] a história é quer uma série de acontecimentos, quer a narração desta série de 


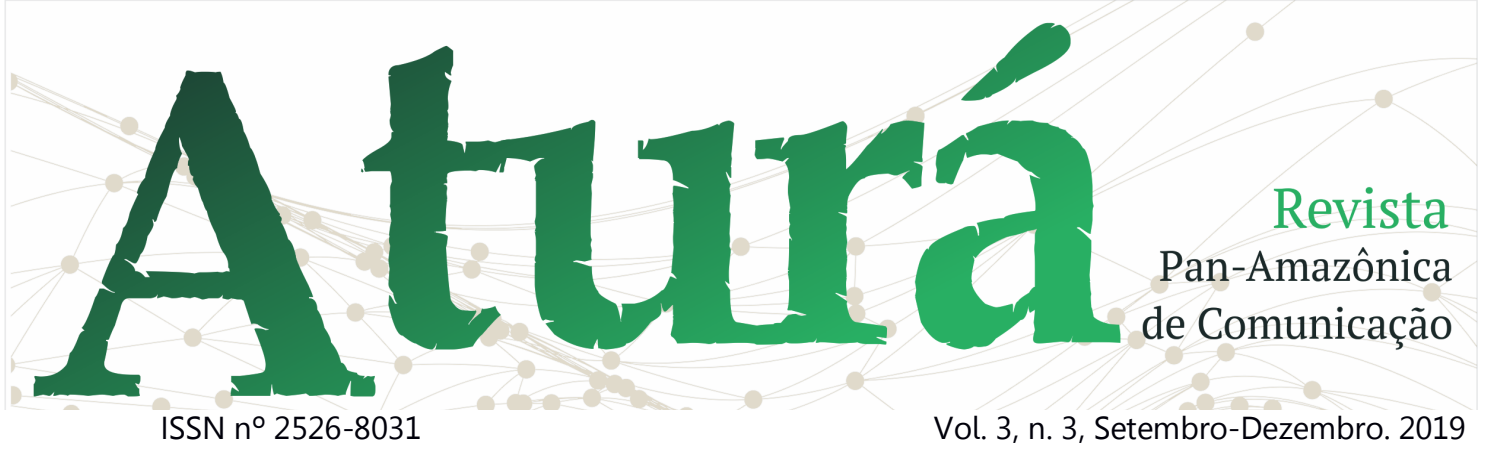

acontecimentos. Mas a história pode ter ainda um terceiro sentido, o de narração (LE GOFF, 2013, p. 13).

Como uma compilação de fatos que tiveram grande repercussão, a história busca conhecer as ações realizadas pela humanidade e lança seus esforços para se estabelecer como ciência histórica. Através da periodização, os acontecimentos mais importantes da vida da nação são resumidos e registrados na tentativa de salvá-los para a posteridade. Muitas vezes as histórias locais se perdem no tempo por não englobarem o todo da nação, ou por representar a parte perdedora de uma disputa constante pelo espaço narrativo. Assim diz-se que a história é contada pelos vencedores, ou seja, as figuras que definem o que será considerado importante na história nacional e sob qual olhar os fatos serão narrados.

Para facilitar o entendimento aos conteúdos passados, a história apresenta linhas de separações que organizam a sequência de acontecimentos, dividindo os séculos em períodos, as épocas ou a forma como o conteúdo sobre a história política de um país é ensinado nas escolas (HALBWACHS, 1990). Sobre a ditadura militar no Brasil, em geral, têm-se acesso, na escola, a um resumo dos principais fatores que levaram ao golpe e que se desenrolaram nas décadas vindouras, como os presidentes e as suas ações que obtiveram maiores repercussões.

Para manter os registros das ações humanas a história faz uso de documentos e depoimentos que comprovem como o fato estudado aconteceu. Porém os espaços em branco não deixam de existir, uma vez que mesmo os documentos e depoimentos retratam apenas um recorte, sob um olhar seletamente escolhido em relação ao acontecimento abordado. Para além disso, mesmo os documentos em si subjetividades próprias daquele que o produz, isto é, nenhum documento é isento de ideologias e concepções de mundo.

Nenhum documento é inocente. Deve ser analisado. Todo o documento é um monumento que deve ser desestruturado, desmontado. (...) Os documentos só passam a ser fontes históricas depois de estarem sujeitos a tratamentos destinados a transformar a sua função de mentira em confissão de verdade (LE GOFF, 2013, p. 91).

Deve-se considerar também a ausência de documentos, além daqueles 


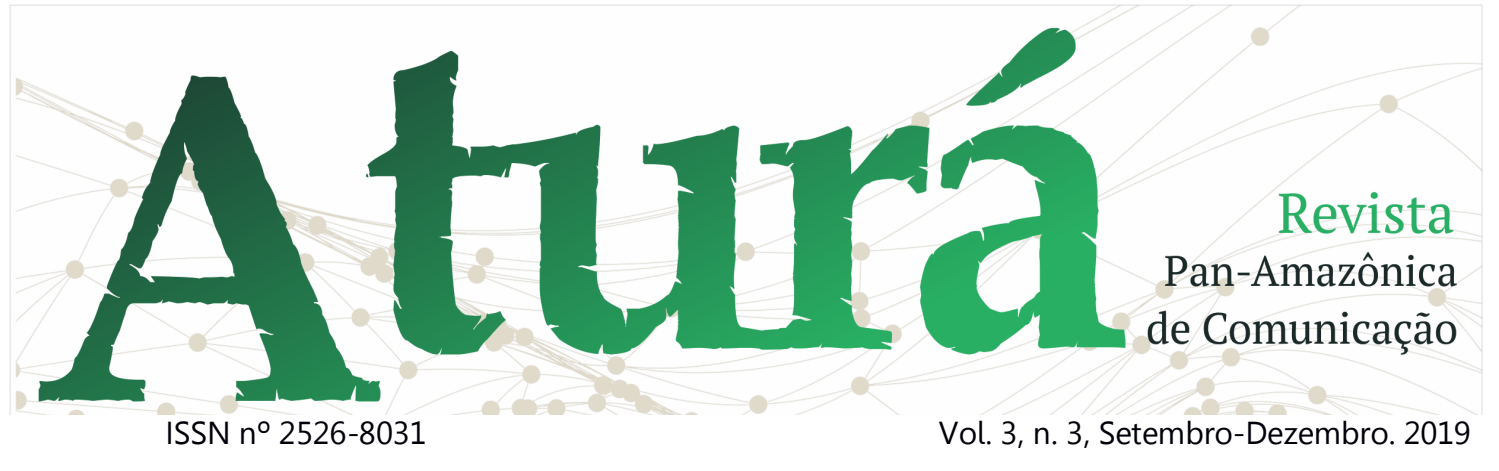

produzidos, registrados e conservados. Os silêncios na história dizem muito. São lacunas que devem ser estudadas a fim de compreender por que aquele espaço está em branco, quais fatos foram esquecidos ou silenciados naquela história e por quais motivos. A história se faz tanto pela presença quanto pela ausência de documentos e arquivos. No período da ditadura militar e até mesmo em buscas recentes feitas pela Comissão Nacional da Verdade, muitos documentos não puderam ser encontrados. Isto porque o ocultamento e a destruição de arquivos no período da ditadura militar brasileira foram amparados pelo Decreto 79.099, de 6 de janeiro de 1977. O decreto estabelecia que documentos considerados sigilosos deveriam ser destruídos pela autoridade que os criasse ou pela autoridade que detivesse sua custódia. Muitos documentos que não foram destruídos estão ainda escondidos dos olhos da sociedade.

Além da história a memória também aparece como uma das formas de consolidação da identidade coletiva e comunitária. As cidades se tornam arquivos urbanos cheios de histórias com as quais convivemos e de onde tiramos memórias individuais e coletivas. Como destaca Halbwachs (1990), mesmo um indivíduo sozinho é apanhado por forças sociais que atuam sobre ele e fazem com que nunca esteja, de fato, só. Com lembranças apoiadas nas de outros e nos grupos sociais nos quais está inserido, como família, escola, igreja, entre outros, as memórias se organizam de forma individual e coletiva, podendo "ora se agrupar em torno de uma pessoa definida, que as considere de seu ponto de vista, ora distribuir-se no interior de uma sociedade grande ou pequena, de que elas são outras tantas imagens parciais" (HALBWACHS, 1990, p. 53).

\section{Lugares de História e Espaço Urbano}

A memória pode se manifestar de diversas formas e se estruturar através de pontos de referências. Os lugares de memória constituem-se como lugares materiais, simbólicos e funcionais, cujo aspecto de obrigação de lembrança, reitera o esforço do que não se deve esquecer. 


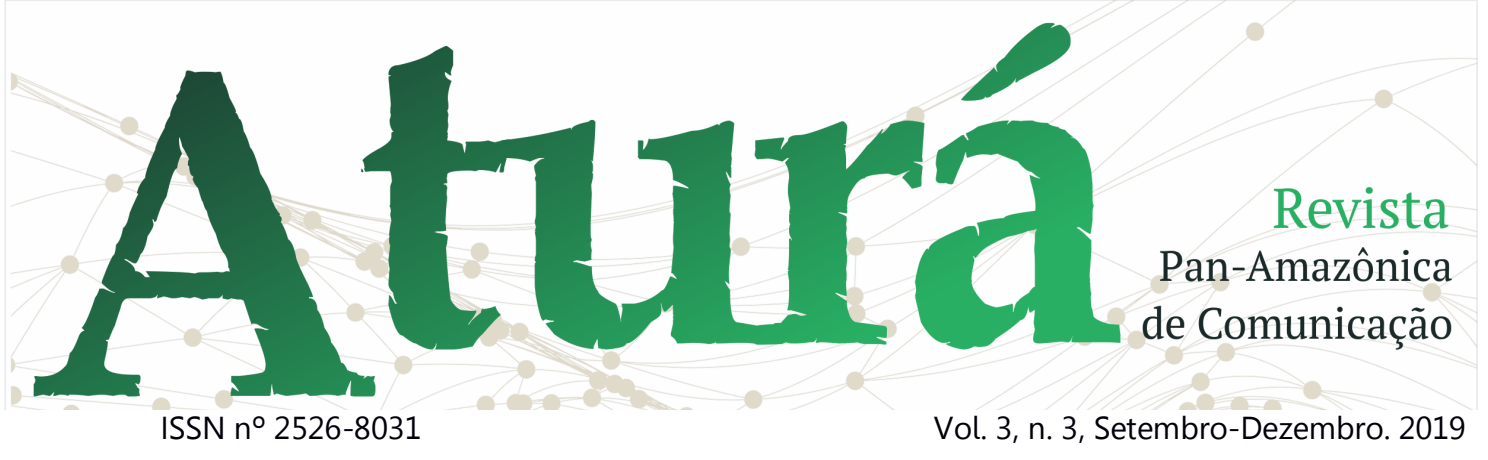

São lugares, com efeito nos três sentidos da palavra, material, simbólico e funcional, simultaneamente, somente em graus diversos. Mesmo um lugar de aparência puramente material, como um depósito de arquivos, só é lugar de memória se a imaginação o investe de uma aura simbólica. Mesmo um lugar puramente funcional, como um manual de aula, [...], só entra na categoria se for objeto de um ritual. Mesmo um minuto de silêncio, que parece o exemplo extremo de uma significação simbólica, é ao mesmo tempo o recorte material de uma unidade temporal e serve, periodicamente, para uma chamada concentrada da lembrança (NORA, 1993, p. 21-22).

Vilhena, município do interior do estado de Rondônia, possui uma população aproximada de 100 mil habitantes, segundo censo de 2017 do Instituto Brasileiro de Geografia e Estatística (IBGE). Fundada em 1977, com 40 anos de fundação, completados em 2017, a cidade não possui, de fato, lugares de memória na cidade. Já os lugares históricos são vários, uma vez que podem surgir como arquivos, monumentos, museu e até cemitérios. Como não carregam a aura ritualística dos lugares de memória, tornam-se espaços de preservação, chamados lugares de história.
Os lugares de memória nascem e vivem do sentimento que não há memória espontânea, que é preciso criar arquivos, que é preciso manter aniversários, organizar celebrações, pronunciar elogios fúnebres, notariar atas, porque essas operações não são naturais. (...) Sem vigilância comemorativa, a história depressa os varreria (NORA, 1993, p.13).

Ao nomear ruas, avenidas e até mesmo escolas tenta-se registrar de alguma forma o momento vivido, ou ao menos as figuras consideradas merecedoras de serem recordadas. Para que o objetivo seja alcançado é necessário que as pessoas mantenham lembranças e conhecimentos sobre os locais e figuras, tornando possível o arquivamento dessa história por meio da nomeação dos locais. Para isto, muitas vezes precisam-se preparar datas comemorativas, por exemplo, para que a memória de quem foi a pessoa que dá nome ao local não seja esquecida. Esse aspecto na cidade já pôde ser percebido em pesquisa anterior (MARTINS; FARIAS, 2018; MARTINS; SILVA, 2019), quando se observou que a maioria das pessoas que moram nas ruas e trabalham na escola que homenageiam os ditadores militares não conhece sequer o presidente do país, mesmo de um período turbulento, que 


\section{A

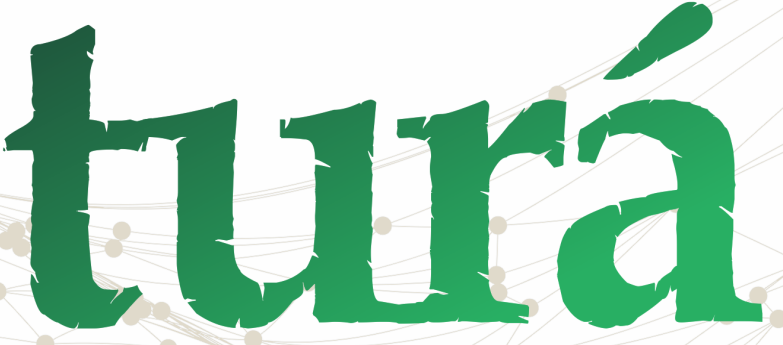 \\ ISSN n² 2526-8031 \\ Vol. 3, n. 3, Setembro-Dezembro. 2019}

nomeia o espaço onde interage cotidianamente.

Os lugares e os dispositivos são concebidos para trazer a consciência das pessoas e de uma sociedade, eventos e homenageados que estariam inclinados ao esquecimento. Uma das formas pelas quais é possivel armazenar essas homenagens, por assim dizer, é através da nomeação de ruas, que se configuram em "arenas memoráveis". As cidades apresentam-se como espaços de resquícios da história, em que, de tempos em tempos, algumas memórias sobressaem-se enquanto outras ficam escondidas. A principal função desses espaços é trazer o passado para o presente. As figuras históricas homenageadas contam não apenas as histórias delas próprias, como também refletem um retrato social de nossa organização atual, das memórias que escolhemos, enquanto nação, guardar ou deixar à margem.

As ruas nomeadas representam o que foi considerado historicamente significativo de ser guardado na memória pública (ALDERMAN, 2002). A nomeação desses espaços se configuram em um importante mecanismo de construção da memória histórica. A arbitrariedade das escolhas de datas e símbolos fica evidenciada, deixando à mostra as motivações culturais, políticas e sociais (DIAS, 2012). Isto fica evidenciado em Vilhena, por exemplo, na nomeação de uma escola e de 15 ruas e avenidas, cujos nomes prestam homenagens a militares.

Essas escolhas, contudo, não são harmônicas, mas conflituosas e estão em constante mudança. Em Vilhena, houve casos de escolas cujos nomes foram alterados por fazerem referência à família Donadon, que deteve o poder político na cidade em quatro momentos da história do município. A alteração nos nomes gerou debate e dividiu opiniões sobre a necessidade da mudança. No Brasil, em 2014, na ocasião do aniversário de 50 anos do golpe civil-militar e dos trabalhos da Comissão Nacional da Verdade, de 2012 a 2014, existiu um engajamento em prol das discussões e das renomeações dos espaços públicos que homenageiam personagens apoiadores da ditadura militar brasileira. No país, 717 escolas homenageiam presidentes da ditadura militar, dessas apenas 20 são privadas e 697 são públicas. 


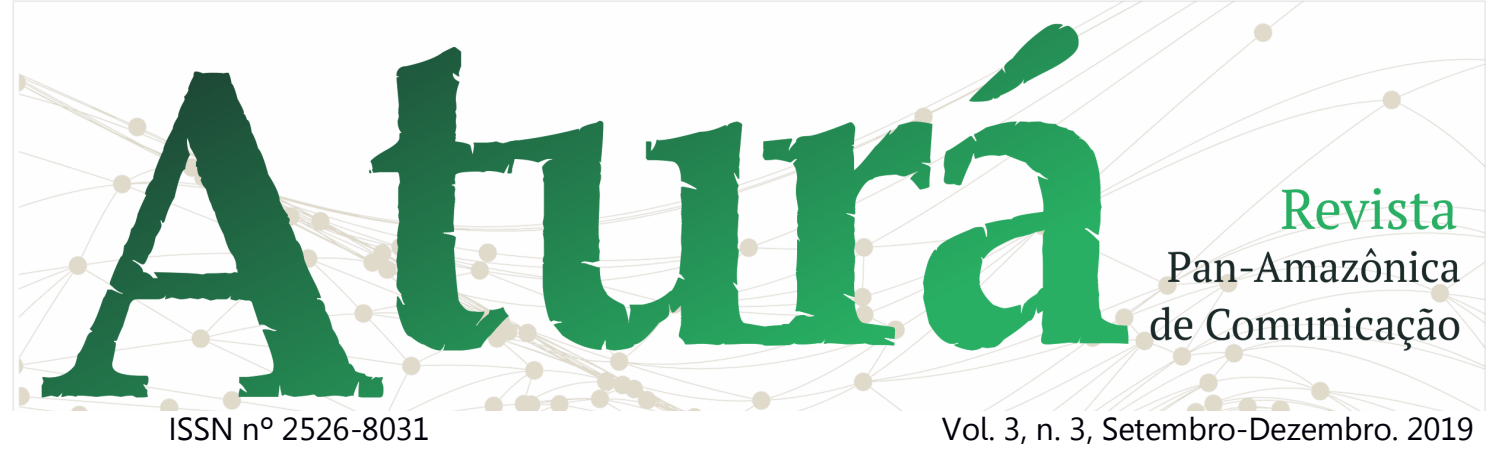

Castelo Branco é o mais homenageado com 347 instituições, Costa e Silva com 209, Medici com 120, Geisel com 23 e Figueiredo com 18 (MARTINS; SILVA, 2019).

Associada às lembranças ligadas a monumentos e lugares, aparecem memórias socialmente construídas que podem indicar a representação de marcos identitários e referências culturais urbanas. Nesse processo, são elaboradas ausências e silêncios que tornam possível negar fatos, enaltecer personagens ou jogá-los no esquecimento (DIAS, 2012). Entre os principais requisitos para que uma figura seja considerada digna de ser homenageada, está a reputação. Nesse sentido, a "política de reputação" é "uma abordagem que centra-se na natureza socialmente construída e contestada de comemorar figuras históricas e as rivalidades discursivas subjacentes à memorização dessas figuras" (ALDERMAN, 2002, p. 100, tradução nossa) $)^{3}$. A reputação histórica de uma pessoa pode ser usada e controlada por atores sociais que buscam

3 Tradução nossa: "is an approach thatfocuses on the socially constructed and contested nature of commemorating his-torical figures and the discursive destacar sua própria agenda comemorativa em detrimento de outras.

Para isso, realizam-se modelagens de controle de reputações históricas, com as imagens construídas e mantidas a fim de controlar as interpretações a respeito de uma mesma figura. Em documento oficial sobre o Histórico da Escola Rural Castelo Branco de Vilhena, é citado que, "de comum acordo com a comunidade, escolheu o nome de Castelo Branco. Em homenagem ao grande estadista nas eleições de 64", em seguida, são apresentados 0 histórico escolar do homenageado, bem como seu histórico profissional, sempre de maneira positiva enaltecendo os feitos de Castelo Branco, para justificar sua escolha como homenageado (MARTINS; SILVA, 2019). Esses feitos, atualmente, ao serem revistos, revelam as negligências e os crimes cometidos na época.

Dessa forma, os nomes nos lugares privados e públicos (MARTINS; MIGOWSKI, 2016; MARTINS; FARIAS, 2018; MARTINS; SILVA, 2019) servem como arenas em que se

rivalries that underlie the memorialization ofthese figures". 


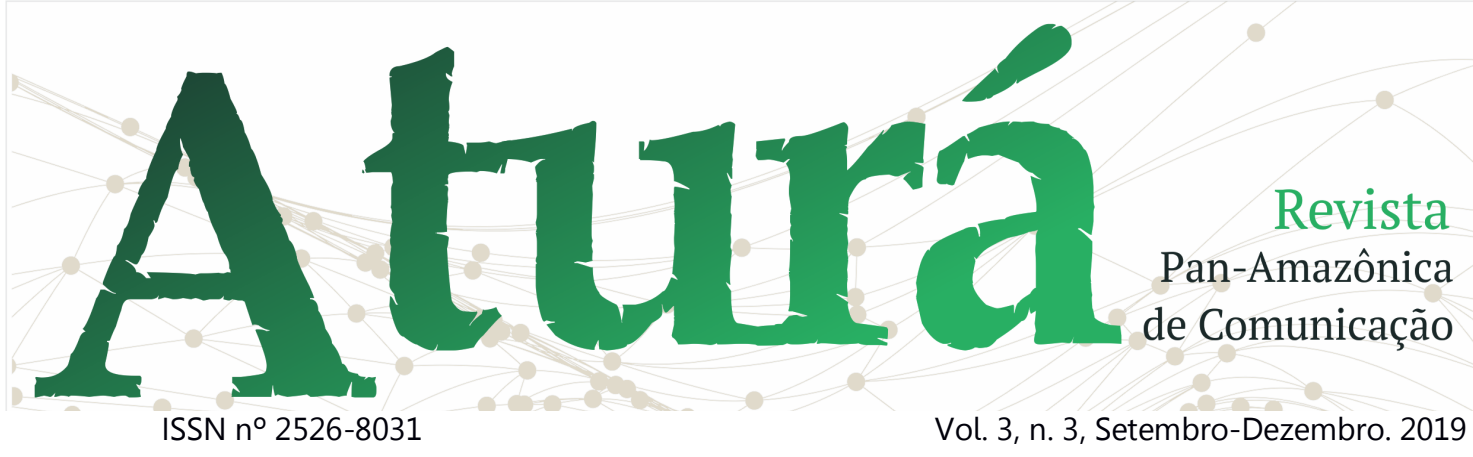

torna possível definir reputações, debater valores e reconhecer o papel que essas figuras desempenham. Além da reputação, outras características surgem como relevantes, como a legitimidade da comemoração, o valor político de lembrar-se de alguém; a ressonância da comemoração, fazer uma figura comemorativa universalmente relevante ou ressonante para os vários grupos sociais que constituem o público; e o hibridismo de comemoração, que se refere às complicações políticas que podem surgir quando atores sociais têm múltiplos interesses comemorativos (ALDERMAN, 2002). A legislação que normatiza a denominação de logradouros costuma estabelecer ainda que as homenagens a pessoas atendam aos dois critérios básicos: que seja falecida e que, em sua biografia, constem relevantes serviços prestados à cidade, ao país ou à humanidade (DIAS, 2012).

A nomeação de ruas não só fornece orientação espacial da cidade, como

4 Tradução nossa: "Commemorative figures function as cultural systems; serving both as "models of society" that reflect how society shapes the past to consolida, naturaliza e legitima uma visão seletiva do passado. Os mapas, listas telefônicas, e até mesmo cartazes de propaganda inscrevem mensagens comemorativas no cotidiano da vida urbana (ALDERMAN, 2002). Dessa forma, além da importância cultural dos nomes das ruas, tem-se também aspectos políticos que cercam a lembrança de determinadas figuras históricas. Ao nomear são escolhidos não apenas aqueles que serão lembrados, mas também, de forma indireta, aqueles que serão esquecidos (DIAS, 2012; MARTINS; SILVA, 2018).

As figuras comemorativas funcionam como sistemas culturais, servindo como "modelos de sociedade" que refletem como a sociedade molda o passado para servir a seus interesses e necessidades atuais, e "modelos para a sociedade" que orientam como a sociedade molda suas ações e atitudes através de uma comparação com o passado (ALDERMAN, 2002, p. 103, tradução nossa) $)^{4}$.

As interpretações a respeito do passado se modificam com o passar do tempo e o risco de esquecimentos está

serveits present interests and needs, and "models for society" that guide how societyshapes its actions and attitudes through a comparison with the past". 


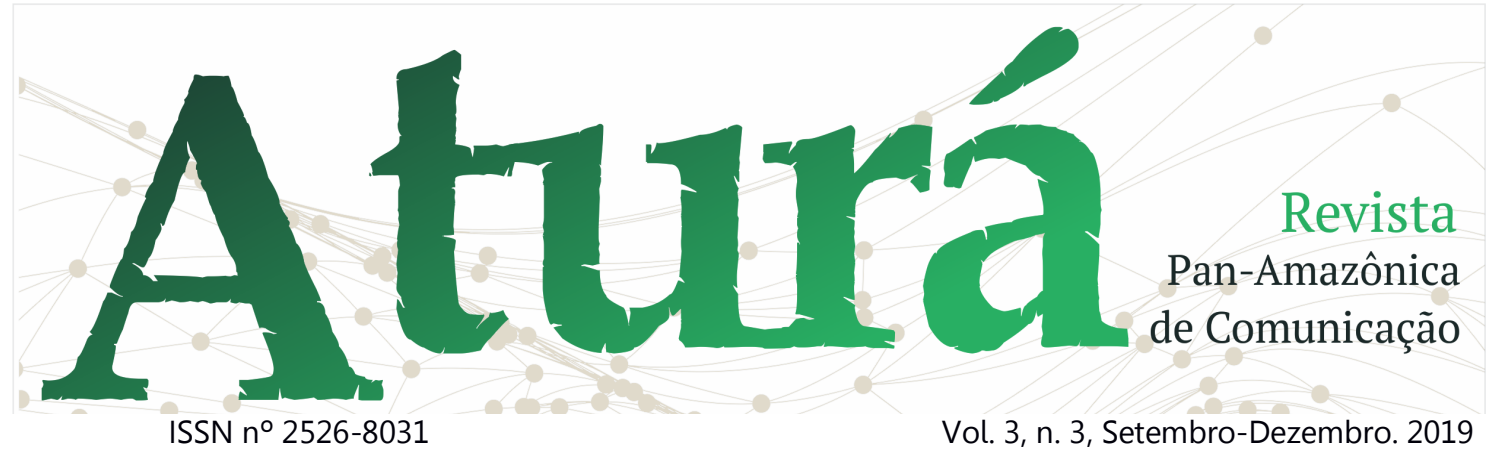

sempre presente. Assim, além da nomeação das ruas, é necessário que seja realizado um acompanhamento para formação e educação, para que o homenageado não seja aos poucos esquecido e para que os fatos e personagens sejam de fato incorporados à vida cotidiana (DIAS, 2012).

Em Vilhena, na nomeação da Escola Municipal de Ensino Fundamental Castelo Branco, por exemplo, houve a tentativa de registro dessa história que foi considerada merecedora de ser recordada. A escola foi criada em 1987, porém, a aparente falta de conhecimento e de recordações sobre quem foi o presidente, por parte de profissionais que trabalham no local, demonstra que o arquivamento dessa parte da história a partir da nomeação do prédio público não foi bemsucedido (MARTINS; SILVA, 2019). A falta de datas comemorativas, como o aniversário de fundação da escola, ou comemoração das datas importantes na história de Castelo Branco fazem com que a memória sobre o homenageado aos poucos seja silenciada.

A partir da nomeação de ruas, é possivel transformar projeções cartográficas em dispositivos de memória que promovem

a narração do espaço urbano através de mecanismos de rememoração coletiva, que registram um ponto de vista sobre a realidade. Para ajudar na rememoração, criam-se os dispositivos de memórias, ferramentas que nos ajudam a lembrar (SILVA et al., 2008). Para compreender melhor os espaços públicos, nos quais as histórias e memórias podem estar impregnados, a cartografia se torna essencial, referindo-se a duas formas de conhecimento sobre o espaço: científico e artístico. A cartografia demonstra, por conseguinte, a intenção de organização espacial.

Os fazeres cartográficos e seus produtos, estão diretamente associados a uma forma de organização do conhecimento sobre o espaço, a uma maneira de conceber, representar e interpretar o mundo, a uma forma de articular saberes e poderes, isto é, a uma configuração imaginária construída a partir de uma perspectiva que privilegia determinados elementos e processos em detrimento de outros (SILVA et al., 2008, p. 2).

Cartografar não se limita à leitura de mapas, para além disso, transforma a cidade em um lugar que orienta e ordena as experiências das pessoas que passam por 


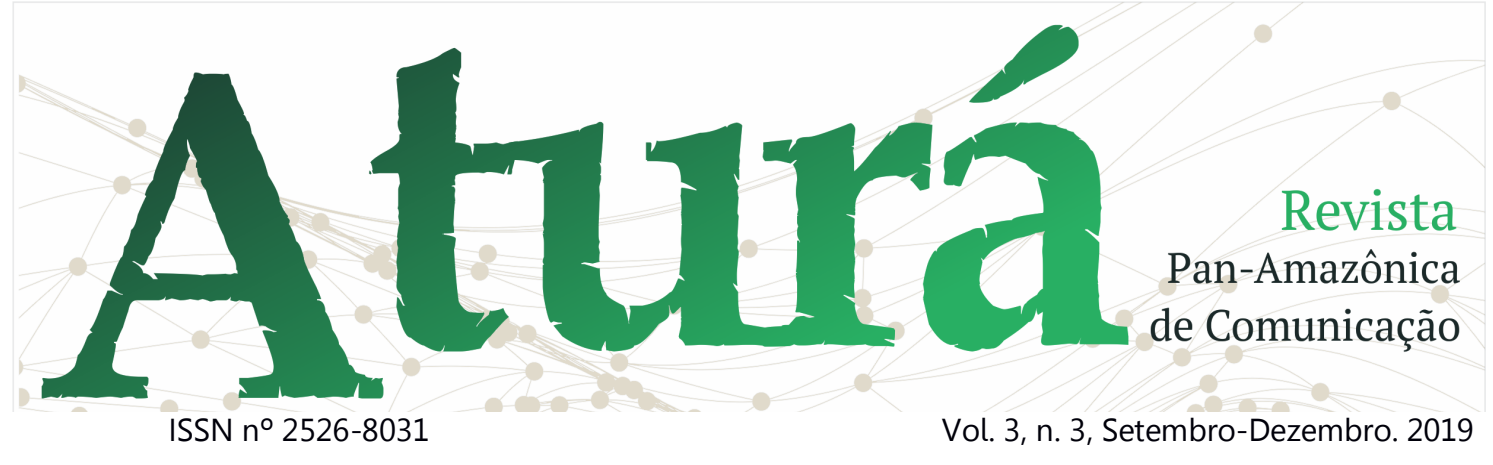

suas ruas. Os usos cotidianos do espaço são a porta de entrada para o estudo da configuração de uma paisagem, que é entendida como resultado dos diferentes significados que circulam por ela. Nas paisagens, processos relacionados a acontecimentos, à memória e à história de um lugar se cruzam (SILVA et al., 2008).

A ambiência urbana, como sua própria etimologia indica, do francês ambiance, cria uma atmosfera própria que envolve pessoa ou coisa. "São práticas que se juntam, colidem, organizam, compõem, participam, desviam, enfim são múltiplas possibilidades de conformação de um todo que nunca se completa, que não tem definição de limites, apenas extensões de fronteiras" (SILVA et al., 2008, p. 9). A apropriação do espaço pelos indivíduos no cotidiano constrói e alimenta essa ambiência, constituindo 0 espaço urbano como objeto social, contribuindo assim para a perspectiva histórica que temos.

A rua permite $\mathrm{o}$ estabelecimento de vínculos mais estabelecidos, embora não necessariamente amigáveis, pela possibilidade de circulação de pessoas e também de espaços públicos de sociabilidade, como ruas, praças e escolas, onde as disputas materiais e discursivas acontecem.

Um espaço de negociação, de disputa tanto do ponto de vista material quanto discursivo. Ele é constituído, utilizado e negociado por grupos heterogêneos e públicos parciais. $\mathrm{O}$ encontro e a negociação contínua de diferentes interesses e concepções de valores, as atribuições de significados - às vezes contraditórios - constituem o que chamamos de espaços públicos (SILVA et al., 2008, p. 13).

Em Vilhena, 9 ruas (General Ozório; Marechal Deodoro da Fonseca; Duque de Caxias; Juscelino Kubitschek; Costa e Silva; Presidente Médici; Getúlio Vargas; Major Armindo Todeschini; Floriano Peixoto), 6 avenidas (Major Amarante; Marechal Rondon; Capitão Castro; Tiradentes; Almirante Tamandaré; Brigadeiro Eduardo Gomes) e a Escola Municipal de Ensino Fundamental Castelo Branco prestam homenagens diretas a militares de diferentes períodos (ver Figura 1), tornando possível visualizar o contexto de criação do município, bem como suas práticas culturais, históricas, políticas e sociais, em espaços de relevância, mais centrais, na cidade. 


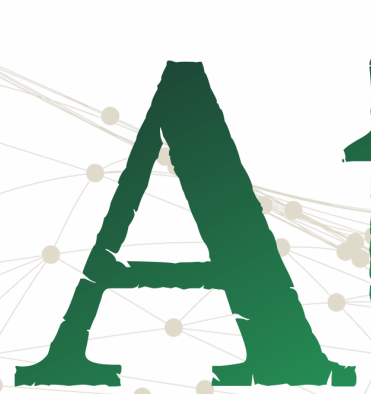

ISSN n² 2526-8031

\section{Revista}

Pan-Amazônica

de Comunicação

Vol. 3, n. 3, Setembro-Dezembro. 2019

Figura 1 - Mapa de Vilhena com avenidas e ruas com homenagens aos militares

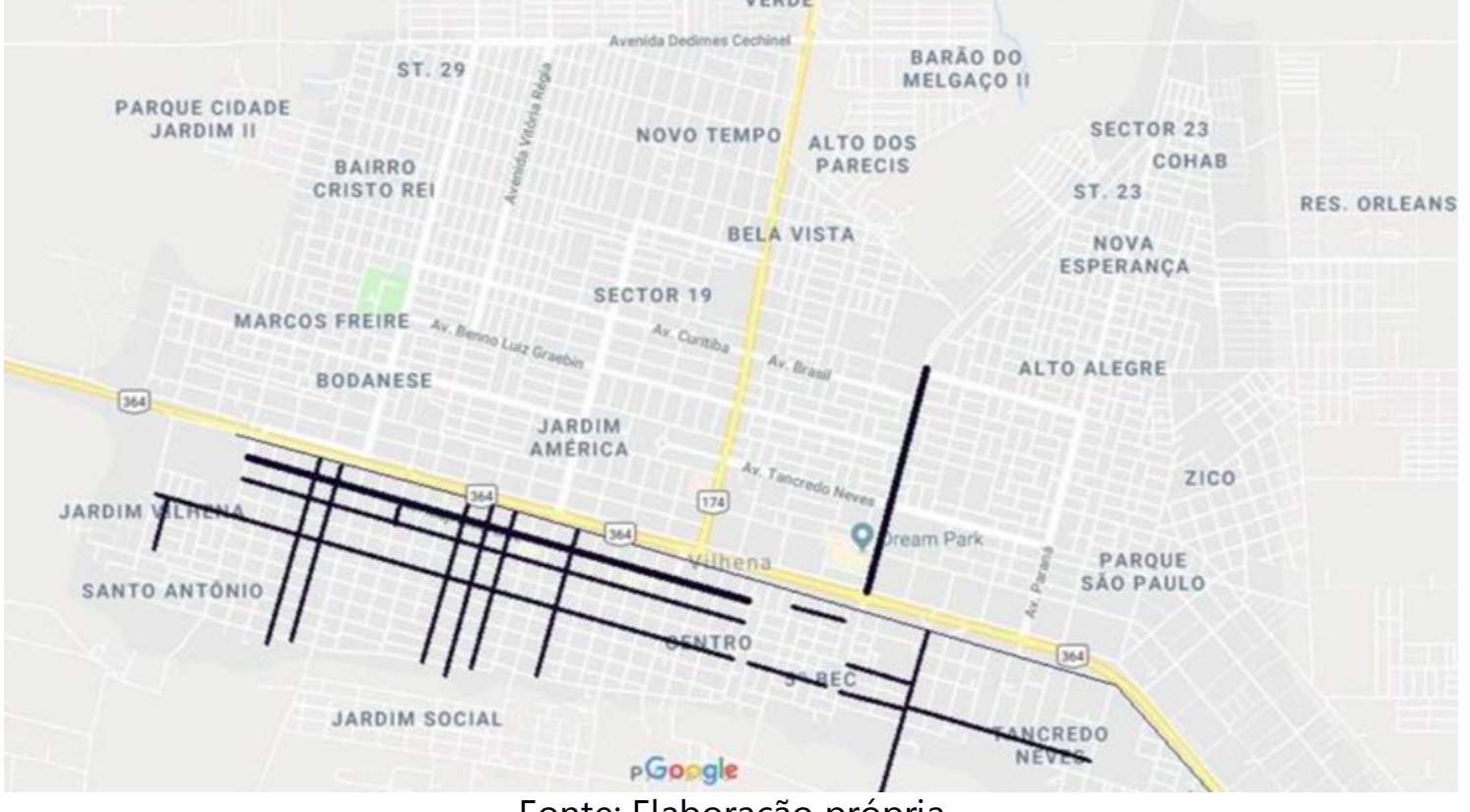

Fonte: Elaboração própria

\section{Considerações Finais}

Nascida no período da ditadura militar, a cidade de Vilhena tem suas histórias e memórias visíveis na constituição do espaço público local. O município possui atualmente uma escola cujo nome faz referência a um ditador militar, a Escola Municipal de Ensino Fundamental Castelo Branco, além de 9 ruas e 6 avenidas que homenageiam militares de diferentes épocas, com a maioria em espaços privilegiados da cidade, com destaque para as avenidas principais e centrais, conforme demonstrado.

O presente trabalho sobre os conceitos de história, lugares de memória e de história e espaço urbano, associados à história de Vilhena e aos resquícios desse período na cidade, através da nomeação da escola e de 15 ruas e avenidas, permite-nos prosseguir em uma pesquisa mais ampla, que visa à investigação, a partir da cartografia do município, dos resquícios históricos de sua 


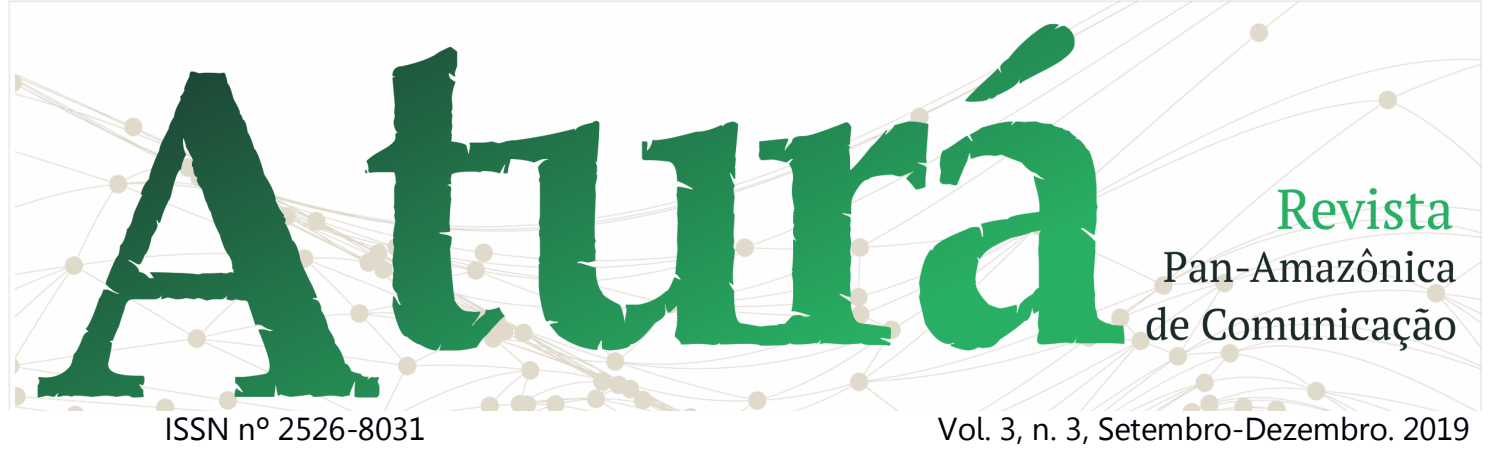

ocupação na construção dos espaços Referências

públicos. Este texto contribui para a delimitação das bases teóricas que serão necessárias nas próximas etapas da pesquisa.

Além da operacionalização dos conceitos acima expostos, como história, lugares de história, espaço urbano, seguiremos um caminho metodológico mais explícito para alcançar os objetivos e encontrar respostas às nossas hipóteses. Propomos um mapeamento dos espaços públicos de Vilhena, através do diálogo e recolhimento de documentos sobre a estrutura e organização da cidade com a Câmara dos Vereadores, as Secretarias de Planejamento, Terras, Transporte e Trânsito e o Gabinete da prefeitura, além da Secretaria de Segurança, Defesa e Cidadania do estado de Rondônia. Nesta etapa, buscaremos informações como: quando essas pessoas foram homenageadas; quem encaminhou a proposta dessas nomeações para a Câmara dos Vereadores; quantos e quem são esses personagens, nacionais ou locais, suas atividades e ocupação, além de procurar entender de que maneira se relacionaram com Vilhena ou mesmo Rondônia.

ALDERMAN, Derek. Street Names as Memorial Arenas: The Reputational Politics of Commemorating Martin Luther King Jr. in a Georgia County. Historical Geography, v. 30, 2002, p. 99-120.

BECKER, Bertha. Amazônia. São Paulo: Editora Ática, 1991.

COLFERAI, Sandro. Imigração e identidade cultural: a representação de uma identidade preferencial no interior de Rondônia. Labirinto, Porto Velho, ano X, $n^{\circ} 13,2010$, p. 102-119.

DIAS, Reginaldo. Sentidos políticos da toponímia urbana: ruas com nomes de mortos e desaparecidos políticos da ditadura militar brasileira. São Paulo: Unesp, v. 8, n.1, p. 155-181, janeiro-junho, 2012.

FIORI, Marcus. Olhares sobre a colonização: O colonialismo manifesto na ocupação de Vilhena. Dissertação (Mestrado em Desenvolvimento Regional e Meio Ambiente). Porto Velho: Universidade Federal de Rondônia, 2012.

HALBWACHS, Michel. A memória coletiva. São Paulo: Centauro, 2006 [1950].

LE GOFF, Jacques. História e memória. São Paulo: Unicamp, 2013 [1988].

MARTINS, Allysson; FARIAS, Khauane. Ditadores militares nas ruas de Vilhena (RO): história e memórias na constituição dos espaços públicos. Parágrafo: Revista 




Científica de Comunicação Social da FIAMFAAM, v. 6, p. 97-109, 2018.

MARTINS, Allysson; MIGOWSKI, Ana. Ditadura militar brasileira e novas formas cartográficas: memórias coletivas e mapas digitais colaborativos. In: ARAUJO, Denize Araujo; MORETTIN, Eduardo; REIA-BAPTISTA, Vitor (Orgs.). Ditaduras revisitadas: cartografias, memórias e representações audiovisuais. Eletrônico: Suporte, 2016, p. 383-402.

MARTINS, Allysson; SILVA, Maria. Escola da ditadura em Vilhena: história e memória de Castelo Branco. In: Anais do XVII Congresso de Ciências da Comunicação da Região Norte (Intercom), Vilhena-RO: UNIR, 2018, p. 1-15.

MARTINS, Allysson; SILVA, Maria. Educação com ditador em Vilhena-RO: história e memórias na Escola Castelo Branco. Revista Observatório, v. 5, p. 322-346, 2019.

NORA, Pierre. Entre memória e história: a problemática dos lugares. Projeto História, $\mathrm{n}^{\circ}$ 10, 1993 [1984], p. 7-28.

RICOEUR, Paul. A memória, a história, o esquecimento. Campinas-SP: Unicamp, 2007.

SILVA, Regina; FONSECA, Claudia; FRANCO, Juliana; MARRA, Pedro; GONZAGA, Milene. Dispositivos de memória e narrativas do espaço urbano: cartografias flutuantes no tempo e espaço. In: Revista da Associação Nacional dos Programas de Pós-Graduação em Comunicação. Brasília: E-compós, v.11, n.1, jan./abr, 2008. 